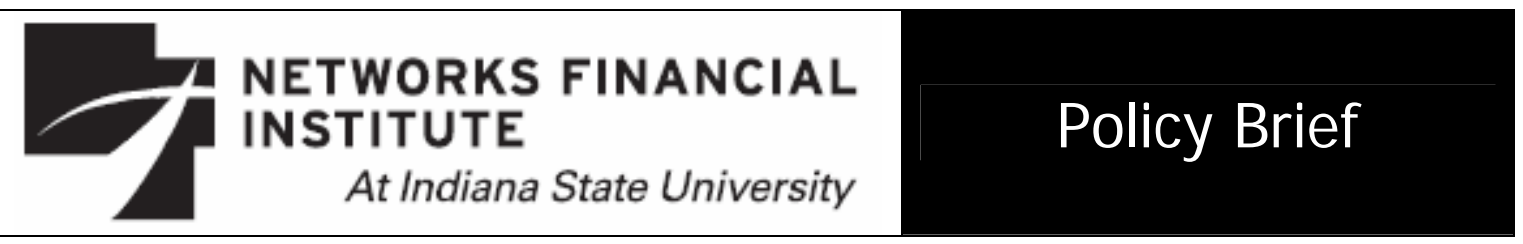

2007-PB-03

March 2007

\title{
Efficiency Consequences of Rate Regulation in Insurance Markets Sharon Tennyson
}

Abstract: Despite the presence of many and diverse sellers of insurance in most markets, insurance prices in some markets remain subject to regulation by state governments. Insurance rate regulation has a long and storied history in this country and the reasons for its continued existence are subject to debate and interpretation. This paper critically examines the arguments for rate regulation and discusses the consequences of this regulation for the insurance marketplace. It first provides a brief overview of the history, scope and objectives of insurance rate regulation, examines the most prevalent justifications for rate regulation and argues that they are incorrect or incomplete. It then turns to the consequences of rate regulation for insurance market outcomes making use of both economic theory and empirical evidence from academic studies of regulated insurance markets. The paper concludes that insurance rate regulation entails high costs for society and for insurance consumers, and that alternative policies for meeting regulatory objectives should be considered.

About the Author: Sharon Tennyson is Associate Professor in the Department of Policy Analysis and Management at Cornell University. Dr. Tennyson is a noted expert on economic and policy issues related to insurance, and has published extensively on topics related to government regulation of insurance markets, insurance fraud, insurance distribution and consumer attitudes and knowledge of insurance. Her research has received funding from a variety of sources including the National Science Foundation, and has been published in high quality economics, insurance and finance journals and in prestigious edited collections. Dr. Tennyson is a member of several national organizations and editorial boards, and is a past president of the Risk Theory Society. She holds a Ph.D. in economics from Northwestern University, and was previously on the faculty of the Wharton School of the University of Pennsylvania. She originally hails from Evansville, Indiana.

Keywords: insurance, rate regulation,

The views expressed are those of the author and do not necessarily reflect official positions of Networks Financial Institute. Please address questions regarding content to Sharon Tennyson at st96@cornell.edu. Any errors or omissions are the responsibility of the author.

$\mathrm{NFI}$ working papers and other publications are available on NFI's website (www.networksfinancialinstitute.org). Click "Research" and then "Publications/Papers." 


\section{Efficiency Consequences of Rate Regulation in Insurance Markets* Sharon Tennyson}

\section{Introduction}

Despite the presence of many and diverse sellers in most insurance markets, insurance rates remain subject to regulation by state governments. Many states directly regulate insurance rates for all consumers, the relative rates charged to different groups of consumers, or the rates charged to the highest risk consumers. States may also regulate the way that rates are determined, for example by regulating insurers’ risk classification practices or limiting expense charges, and in this way affecting the premiums paid by consumers. The extent of regulation varies by state and by type of insurance, but government intervention in some aspects of insurer price-setting is common throughout the industry.

The reasons for continued rate regulation are the subject of much debate. Economic theory fails to provide a clear rationale for insurance rate regulation, and the empirical record suggests that insurance markets in which rates are unregulated perform as well or better in most respects than more closely regulated markets. Studies of the determinants of regulation conclude that regulation follows the patterns predicted by theories of politically determined regulation (in which self-interested groups use regulation to further their interests). ${ }^{1}$ Consistent with this view, the advocates and opponents of regulation tend to emphasize different objectives, and regulators are often required to trade off between these objectives.

\footnotetext{
* Forthcoming reprint in the NAMIC Review of Insurance Politics, June 2007.

This paper was prepared for "4th Annual Insurance Reform Summit" a conference sponsored by Networks Financial Institute at Indiana State University and held in Washington, D.C. on March 07, 2007.

${ }^{1}$ See, for example, Joskow, 1973; Cummins, Phillips and Tennyson, 2001; Harrington and Danzon, 2001.
} 
This paper critically examines the arguments for rate regulation and discusses its consequences for the insurance marketplace. To provide an organizing framework for the discussion, the paper first provides a brief overview of the history, scope and objectives of insurance rate regulation. It then examines the most prevalent justifications for rate regulation and argues that they are incorrect or incomplete. The main sections of the paper focus on the consequences of rate regulation for insurance market outcomes, making use of both economic theory and empirical evidence from academic studies of regulated insurance markets. The paper concludes that insurance rate regulation entails high costs for society and for insurance consumers, and that alternative policies for meeting regulatory objectives should be considered.

\section{History, Scope and Objectives of Rate Regulation}

Insurance rate regulation has a long and storied history in this country. Because of early judicial interpretations that insurance did not meet the definition of "commerce" that would allow federal pre-emption of states' authority in interstate insurance dealings, insurance regulation is largely undertaken by the individual states rather than by the federal government. Regulation has many common elements across the states, and states' regulatory activities are coordinated through the National Association of Insurance Commissioners (NAIC), a voluntary association of state regulatory authorities. Every state regulates insurer solvency, sales practices, agent licensing and policy forms, for example. However, there is much greater variation across the states in the extent to which insurance rates or insurer pricing practices are regulated.

Direct regulation of insurance rates arose due to the dual concerns of monopoly pricing if insurers were allowed to pool information for rating purposes, and concerns 
that “destructive competition” or under-pricing for market share would lead to price instability and insolvencies if they were not. Prior to 1944, U.S. insurance sellers colluded openly and legally, sharing data and jointly setting prices. The economic rationale for this arrangement was that the pooling of data across a larger number of observations made predictions more reliable for the industry and reduced aggregate risk as a result. Nonetheless, state regulation of insurance rates was one mechanism used for enforcing price stability beginning in the early $20^{\text {th }}$ century. When antitrust legislation was finally and belatedly extended to the industry in 1944, federal legislation in the form of the McCarran Ferguson Act granted insurers a partial exemption to allow continued pooling of data. This partial antitrust exemption was conditional on state oversight of the industry, which states interpreted as mandating the regulation of insurance rates. Thus, insurance rate regulation became nearly universal.

However, in keeping with the deregulatory trends throughout the economy, many states began to move away from insurance rate regulation and toward competitive rating systems in the 1970s. Because the pace and scope of deregulation has varied across states, the extent to which insurance rates are regulated varies greatly. Some states deregulated rates for only some lines of insurance, and other states have reinstated regulation for some insurance lines after experiments with competition. In many cases, states that reintroduced rate regulation did so in during times of high premium inflation and regulation was accompanied by mandatory rate rollbacks. ${ }^{2}$

There are many different forms of rate regulation laws employed by the states. In

\footnotetext{
2 Notable examples include Massachusetts' reinstatement of auto insurance regulation in 1979 after a one year experiment with competition, accompanied by mandatory rebates; California's Proposition 103 in 1988, which instituted prior approval regulation and a $20 \%$ rate rollback for all property-liability lines of insurance; and Texas’ medical malpractice rate rollbacks in 1995.
} 
a few states and insurance markets, rate regulation requires insurers to charge uniform rates that are determined by an insurance bureau and approved by the state insurance commissioner. Under these state-made rating systems, insurers may sometimes charge less than the state-made rates, but they must obtain prior approval of the insurance commissioner before doing so. Under a state-made rating system other aspects of insurance rate-setting including the determination of rating classes, relative rates across classes, and the setting of experience rating surcharges and discounts are also common across all insurers and determined by the insurance commissioner.

The most widespread form of insurance rate regulation is a "prior-approval" system. Under prior-approval regulation, insurers are required to file proposed rate adjustments with the insurance commissioner in advance of introducing rates into the market. The commissioner reviews the filed rates and supporting documentation, and approves or denies the rate change. Prior-approval regulation does not require insurers to charge uniform rates. Rather, insurers may determine their own rates but must justify the rates relative to loss and expense experience in order to satisfy regulatory requirements for allowable rates of return.

In other states insurers are required to file their rates with regulators but may use the rates without regulatory approval. If, after review within a permitted time period the filed rates are found to be unacceptable by the regulator, they must be withdrawn and premiums adjusted to reflect approved rates. However, these "file and use" or "use and file" systems are largely passive in their responses to rate filings. A few state laws are file-only, so that rates must be filed with the insurance commissioner but are not subject to review or disapproval. 
In an increasing number of states, flex-rating or band-rating approaches to rate regulation are employed, forming a middle ground between prior approval-regulation and file-and-use or file-only systems. Under flex-rating, insurer rate changes that fall within a pre-specified percentage range are subject only to file-and-use or file-only requirements. Rate changes larger than this percentage are subject to prior-approval regulation.

States with state-made, prior-approval or flex-rating systems are generally characterized as actively regulating insurance rates. States with filing-based regulatory systems are generally characterized as having competitive rating; however, it should be remembered that these states exercise some regulatory oversight of insurer pricing.

Even in states that actively regulate insurance rates, regulation does not apply to all lines of insurance. Rate regulation is most commonly employed in automobile, health, homeowners', workers' compensation and medical malpractice insurance. Recent industry statistics show that 21 states actively regulate automobile insurance rates and 18 states regulate homeowners’ insurance rates, most using prior-approval systems; 18 states impose rating restrictions in individual health insurance and 49 states impose restrictions in small employer group health plans. Medical malpractice insurance rates are regulated in 19 states, and the most recent information available suggests that 38 states regulate workers' compensation insurance rates. In contrast, only 7 states actively regulate rates for other commercial insurance policies, and life insurance rates are not regulated by the states. $^{3}$

\footnotetext{
${ }^{3}$ Data for automobile, homeowners and commercial insurance are for 2006 and were obtained from the Insurance Information Institute; data on individual health insurance are for 2004 and were obtained from Georgetown University Health Policy Institute; data on medical malpractice are for 2003 and were obtained
} 
In virtually all states, the legislation that enables rate regulation puts forward the objectives of rates that are adequate, not excessive, and not unfairly discriminatory. Promoting rate adequacy reflects concerns about underpricing in the industry, fueled at least in part by an early history of pricing cycles and periodic crises in some markets. As noted above, this concern is juxtaposed against concerns about the potential for monopoly pricing. Preventing unfair discrimination reflects concerns about price differences across consumers, especially if unrelated to risk differences.

Over time, the focus of regulation has come to emphasize the objective of preventing excessive rates - either for all consumers or for some groups of consumers. Case-based evidence identifies many instances in which regulators limit across-the-board rate increases to a lower percentage than that requested by the insurer. Formal empirical research also supports the idea that regulators tend to use their oversight authority in this manner. For a variety of sample periods and using a variety of estimation methodologies, econometric studies show that insurance rate regulation reduces the markup of average premiums over losses (i.e., the unit price or inverse loss ratio) and reduces insurer profits, on average. ${ }^{4}$ These studies have also found, however, that regulatory stringency varies a great deal across states. Overall, the impact of regulation varies substantially across states, across lines of insurance, and across time, due not only to differences in regulations but also to differences in regulatory implementation.

Some states’ regulations are targeted to preventing excessive rates for selected groups of consumers. These states' rate statutes or regulations require leveling of rate

from the National Association of Insurance Commissioners; data on workers' compensation insurance are for 1995 and were obtained from Barkume and Ruser (2001).

${ }^{4}$ See Cummins, Phillips, and Tennyson (2001); Grabowski, Viscusi, and Evans (1989); and Harrington (1987, 2002), among others. 
differences across risk classes, or restrict the factors that may be used for rating purposes. Rating regulations in individual and small employer group health insurance markets generally take this form, restricting rate differences across consumers with different health status. In automobile insurance, a recent survey suggests that a large number of states restrict the rating factors that insurers are allowed to use, and a few states restrict relative rates across driver classes or territories. ${ }^{5}$ Restrictions of this type reduce premium differences across high-risk and low-risk consumers, in the interests of advancing price equity or insurance affordability for high-risks.

Additional restrictions on the premiums charged to the highest-risk consumers occur in some insurance markets, through the operation of state "residual" markets (sometimes called "involuntary" or "high-risk" pools). Residual market mechanisms provide insurance to consumers who are unable to obtain coverage from a private insurer at market rates. Residual market insurance is offered at subsidized rates subject to priorapproval regulation or state determination of rates, with the associated losses from the pool funded in some manner by the remainder of the market. Every state operates a residual market for automobile, workers' compensation and medical malpractice insurances, and 33 states have a residual market for homeowners' insurance; 32 states operate a high-risk pool for individual health insurance.

\footnotetext{
${ }^{5}$ Weiss, Regan and Tennyson (2005) report that 21 states restrict rating factors and 10 states restrict relative rates.
} 


\section{Is There a Case For Insurance Rate Regulation?}

Chief among the arguments for insurance rate regulation is that insurance markets do not function competitively and/or that consumers lack the information or expertise to assure that the prices they pay are reasonable. However, a large body of academic research supports the conclusion that insurance markets function in a workably competitive manner in the absence of rate regulation. ${ }^{6}$ Unregulated insurance markets contain a large number of sellers, exhibit relatively small hindrances to firm entry and exit, and firms offer reasonably similar products. Measures of market concentration tend to be low, with the largest four firms serving less than 50 percent of the market and Herfindahl index numbers within the ranges that meet regulatory standards for competition. Although a certain amount of capital is required to enter insurance, incorporation restrictions are often relatively low even in view of minimums set by insurance regulators, and thus entry into insurance markets is vigorous in good times.

The pricing and profit dynamics in the industry, measures of economic profit rates and rates of return on firm equity suggest that prices and profits in unregulated insurance markets are not excessive and are reflective of competition across firms. Studies of price inflation in insurance markets generally point to rising loss costs as the main driver of premium increases. Tellingly, in periods of high price inflation insurer profit measures tend to be falling rather than rising, indicating that price increases are not driven by anticompetitive pricing. ${ }^{7}$ This suggests that insurance prices are reacting to changes in exogenous market forces, and that the drivers of price inflation will not be resolved by regulatory price controls.

\footnotetext{
${ }^{6}$ This is distinct from the theoretical idea of perfect competition, which imposes too many requirements to be a realistic description of actual markets. See Clark (1940) and Scherer (1980).

${ }^{7}$ Cummins and Tennyson (1992) study the dynamics of premiums and losses in automobile insurance.
} 
Despite the fact that insurance markets show strong evidence of competition, not every consumer faces low insurance prices or even prices that he/she finds affordable. This may be an important source of demand for rate regulation. A fundamental requirement of insurance pricing in a competitive market is that prices reflect the expected value of a consumer's insured losses. Consumers who face greater accident risk face higher insurance premiums to reflect the greater risk they impose on the insurance system. Insurance pricing is not perfectly correlated with risk, however, as insurers must set premiums based on observable characteristics that they find to be correlated with loss experience. Insurers may also adjust premiums over time based on observed loss experience since this provides a signal of the expected value of future losses. Because premium variation is more readily visible than risk variation, high prices or large price differences across consumers may lead to the perception that insurance premiums are unfairly determined or unfairly discriminatory. ${ }^{8}$ As a consequence, insurance rate regulation often arises in response to a desire to assure affordable insurance coverage for all (or at least most) consumers.

It is notable that the markets in which rate regulation is most common automobile insurance, health insurance, workers compensation, medical malpractice and homeowners' insurance - are all markets in which insurance is mandatory or in which universal insurance coverage is thought to be socially desirable. In these markets it may be in society's interest to have all individuals insured because lack of one's own insurance confers specific financial risks onto others or onto the remainder of society.

Desires for universal coverage in automobile insurance reflect concerns about uncompensated accident losses being imposed on other drivers by those who drive

\footnotetext{
${ }^{8}$ For example, see the consumer polling data discussed in Jaffee and Russell, 1998.
} 
uninsured. Health insurance coverage is most often seen as a fundamental right to protect or guarantee individuals' health and until recently has not been viewed as an appropriate target for compulsory coverage. But in this case as well, the uninsured may impose external costs on the insured due to the need to spread the costs of uncompensated care across the remainder of the market. Workers' compensation insurance is purchased by employers to protect against the risk of employee on-the-job injuries, for which employers are by law financially responsible. Many states require most employers to purchase workers compensation insurance as a means to guarantee the financial resources to pay losses, which would otherwise be transferred to the injured employee. Medical malpractice insurance has similar risk transfer characteristics and is thought to encourage a healthy supply of medical services. Homeowners' insurance is required by mortgage lenders to protect them from uncompensated loss of financial interest; thus, while not truly compulsory, it is required for most home buyers.

Given the insurance markets that are the focus of rate regulation, it is perhaps less remarkable that the goals of rate regulation include reducing price variation across purchasers. In these markets, rate regulation may be intended as a tool for pursuing the socially desired outcome of universal coverage by reducing price levels for high-risk purchasers. This can be targeted through regulatory limits on rate changes, restrictions on relative rates or on the use of certain rating factors, restrictions on rates in the residual market, and other restrictions on pricing and underwriting.

While the direct and intended effect of these rating restrictions is to limit premium variation across consumers, the indirect effect is to impose premium cross-subsidies from low-risk consumers to high-risk consumers. From a theoretical perspective, there are 
circumstances in which premium cross-subsidies from low-risks to high-risks could improve the wellbeing of all insurance consumers. If high-risk consumers remain uninsured while participating in the insurable activities and their lack of insurance imposes costs on other market participants, then it is possible for all to be better off under a pricing system that provides premium subsidies for the high-risks. ${ }^{9}$ These gains arise if the subsidies cause high-risk consumers to purchase insurance when they otherwise would not, reducing the external costs borne by others. From this perspective, crosssubsidies that increase the rate of insurance among high-risks may benefit society so long as insurance purchase by low-risks is not greatly decreased in the process.

However, a number of difficulties arise in attempting to enforce price crosssubsidies in a market. If insurance purchase is voluntary, the higher prices faced by lowrisks who are forced to subsidize high-risks may in fact cause them to forego insurance or to reduce their purchases. Additionally, the competitive responses of insurers may reduce or eliminate cross-subsidies. Insurers may respond to regulations by categorizing risks based on individuals' consumption of other goods that are correlated with risk. ${ }^{10}$ Insurers may also circumvent regulatory restrictions by offering a menu of policies to induce customers to sort themselves into high and low risk categories, as predicted by certain theoretical models. Finally, premium cross-subsidies may create unintended distortions to consumers' risk behavior by reducing the responsiveness of premiums to changes in

\footnotetext{
${ }^{9}$ Keeton and Kwerel (1984) and Smith and Wright (1992) demonstrate this point using formal theoretical models. Other possible justifications for premium cross-subsidies include risk spreading when the chance of being a high risk is randomly assigned across consumers and desires to redistribute income and premium stability for risk-averse consumers (Pauly, 1970; Abraham, 1985; Blackmon and Zeckhauser, 1991).

${ }^{10}$ For theoretical treatments of these issues see Rothschild and Stiglitz, 1976; Riley, 1979; Wilson, 1977; Bond and Crocker, 1991.
} 
risk. This can undermine the intent of cross-subsidies by raising accident levels and lost costs, leading to higher premiums for all consumers.

\section{The Efficiency Consequences of Rate Regulation}

The discussion of rate regulation makes it clear that there are two potentially distinct effects of price-reducing rate regulation: reducing average rates for all consumers - often termed rate suppression; or reducing rates for some consumers (usually high-risks) relative to others (usually low-risks) - often termed rate compression. ${ }^{11}$

Both rate suppression and rate compression will have negative consequences for insurance markets. Rate suppression runs the risk of driving average premiums below competitive levels, reducing insurer returns below a competitive rate of return. The occurrence or threat of rate suppression will distort insurance supply in the market, reducing competition in the long run. Rate compression may have similar effects by reducing rates for some consumer groups below competitive levels. Both rate suppression and rate compression may also affect consumers' insurance decisions and risk-taking behavior. The net effects of stringent rate regulation of this kind will be to reduce insurance supply and reduce competition in insurance markets, while distorting consumer behavior in ways that lead to higher risk and higher insurance costs.

Even if insurance operations are "profitable" in a regulated jurisdiction, if rates of return are held below the competitive return, then every dollar of capacity that an insurer devotes to the regulated market represents a lost opportunity to earn a higher return on that dollar in unregulated markets or in other ventures. This creates pressure on

\footnotetext{
${ }^{11}$ This terminology was popularized by Harrington (1992), who provides an extensive discussion of the impact of rate suppression and rate compression in insurance markets.
} 
insurance capacity to exit the regulated market. States may impose exit restrictions on insurers, in the form of penalties that must be paid or licenses forfeited if the insurer exits the market. These may dramatically increase the costs of exit, and will succeed in slowing exit from the market. However, exit will still occur if the losses from continued operation exceed the costs of exit. Just as important, rate suppression - especially if accompanied by exit restrictions - will reduce insurers’ incentive to enter a market. Because of this, overly stringent regulation of insurance rates will lead - over the long run - to a market with fewer firms, lower insurance capacity and larger residual markets than in a competitive environment. Existing firms will also have less capital per dollar of loss covered by insurance contracts, leading to greater solvency risk.

Regulatory uncertainty may create a further dampening of competition. ${ }^{12}$ Even if current rates are adequate, uncertainty about future rate adequacy will cause insurers consternation because the value of their fixed investments in the market depends on future rates of return. When faced with regulatory uncertainty, insurers will be less likely to invest in the market, and insurers remaining in the market will have less incentive to make cost-reducing or efficiency-enhancing investments.

Competition will be further dampened because of reduced incentives for insurers to adjust prices to changes in loss or expense conditions. Prices will adjust less frequently because of uncertainty about whether regulators will allow needed adjustments in the future, because of the higher transactions costs of changing prices due to the need for regulatory approval, and because of the delays inherent in obtaining that approval. Infrequent price changes reduce competition; they may also mean that the price changes

\footnotetext{
${ }^{12}$ Regulatory uncertainty arises if the regulatory process that determines allowable rates is uncertain, if regulatory decisions occur only at discrete intervals of time in a changing market environment, or if insurers face regulatory restrictions on denying coverage and on exiting the market, for example.
} 
which do occur are larger - contributing to greater overall volatility of prices and profits in the market.

The characteristics of firms operating in the market may also be distorted by the potential for rate suppression. Single-state insurers may have an unusual set of advantages in regulated markets. Their greater accounting transparency with regard to profit, loss and expense reporting to regulators may aid in rate negotiations. Their structure may also place implicit constraints on regulators with regard to rate adequacy, since single-state firms in a regulated state are more likely to experience financial distress if regulated rates are set too low. However, the consequences for the market of having a large concentration of small single-state firms may be less than beneficial. Small, singlestate start-ups may have higher operating expenses and may face higher insolvency risk due to their smaller capitalization and lower geographic diversification.

As noted previously, a feature of many regulatory systems is cross-subsidies in rates from low-risk to high-risk consumers. Theoretical justifications for cross-subsidies assume that the level of insured risk is fixed and exogenously determined. If this is not the case, then cross-subsidies will distort consumer risk-taking in ways that lead to higher insurance costs.

Cross-subsidies are distorting because they result in insurance premiums that do not reflect the true costs of providing insurance to each consumer. When premiums reflect the expected marginal costs of coverage, consumers have appropriate information on which to base their decisions about insurance purchase and levels of care taken in the insured activity. Premium cross-subsidies reduce the links between risk or loss experience and the insurance premium paid. This will reduce incentives for care and will 
increase risk-taking by consumers, relative to a system in which rates are set

competitively. This increased risk-taking will produce upward pressure on accident rates and losses and ultimately lead to higher insurance premiums. In this case, regulation as a means to reduce price differences across consumers will have unambiguously negative consequences for insurance markets.

There may be an additional upward shift in insured claims and loss costs due to increased incentives for claims filing that is created by rate regulation. Consumers will consider marginal costs and marginal benefits when deciding whether to file a claim. If rate regulation reduces premium differentials across low-risk and high-risk consumers or dampens experience rating adjustments for poor loss experience, the premium consequences of filing a claim or of filing many claims are lessened. This will increase the propensity of consumers to file claims. These same arguments apply not only to legitimate claims, but also to fraudulent or exaggerated claims, providing a potential explanation for the exceptional problems with fraud in some regulated insurance markets.

\section{Empirical Evidence on the Effects of Rate Regulation}

The theoretical discussion has generated two key predictions about the effects of regulation. Regulation will reduce competition - with fewer firms operating, a higher presence of high-cost and/or smaller firms, and larger residual markets than otherwise expected. Regulation will also raise claims costs - due to shifts in insurance purchase patterns, a decrease in consumer safety incentives, and increased incentives for consumers to file claims. Research in several insurance contexts has analyzed the empirical importance of these effects and provides support for these predictions. 
There is substantial evidence that insurance market supply responds adversely to profit suppression and/or regulatory uncertainty. As discussed above, regulatory suppression of rates will lead to pressures for insurers to retrench operations or in extreme cases to exit the market. Empirical studies show that regulated state markets have fewer firms and a higher proportion of high cost and smaller firms (Joskow, 1973; Tennyson 1987). In several highly regulated automobile and workers compensation insurance markets, a substantial number of insurers exited those markets after years of experiencing low profits. Consistent with the predictions of theory, the firms that exited tended to be large, national firms that write multiple lines of insurance.

The recent experiences of deregulating states provide further evidence that these effects are directly related to rate regulation. States that have reformed insurance regulation to allow insurers more freedom in rate setting have seen increased competition, increased insurance availability, and lower prices. Prior to 2003, New Jersey had a stringently regulated automobile insurance market from which over 20 companies had exited over a 10 year period. In the wake of significant reforms passed in 2003, the number of suppliers more than doubled, increasing from 17 companies to 39 . Recent estimates suggest that prices have fallen for most consumers and that thousands of previously uninsured motorists have been added to the insurance system. Since reforms to South Carolina's automobile insurance regulatory system in 1999, the number of insurers writing auto insurance in the state has doubled, rate levels have declined, and the number of uninsured motorists has declined.

Rate regulation has also been shown to reduce insurance availability, as measured by a greater fraction of consumers insured through residual markets. This is consistent 
with the idea that regulation reduces insurance rates for at least some consumers below those that would obtain in the competitive market. Rate cross-subsidies are a big contributor to residual market size, as consumers who receive significant premium subsidies will be insured only involuntarily by profit-seeking insurers. Price subsidies offered in the residual market have also been shown to produce significant cost shifting to consumers in the voluntary market in some states (Harrington, 1993).

A growing body of empirical evidence suggests that - consistent with theoretical predictions - rate regulation does indeed lead to higher average insurance costs. Several recent studies of workers compensation insurance document a link between stringent rate regulation and higher loss costs, premiums and worker injury rates. ${ }^{13}$ Similar results have been found in automobile insurance. Weiss, Regan and Tennyson (2005) find that average loss costs and claims rates per insured car are significantly higher in regulated states, and case studies of the heavily regulated markets in Massachusetts and South Carolina found that loss costs are substantially greater than would be expected based on other market characteristics during periods of stringent rate regulation. ${ }^{14}$ These studies suggest that attempts to reduce insurance prices through regulation may be self-defeating in the long run.

In sum, empirical studies show that insurance rate regulation can substantially distort insurance market outcomes. While regulatory systems vary greatly across the states, and many states apply rate regulation with a relatively light hand, stringent regulation that attempts to move insurance prices a significant distance from competitive prices entails significant efficiency costs and will be unsustainable in the long run. States

\footnotetext{
13 See Danzon and Harrington (2000), Harrington and Danzon (2001), Barkume and Ruser (2001).

${ }^{14}$ See Tennyson, Weiss and Regan (2002) and Grace, Klein and Phillips (2002).
} 
that have used rate regulation in this manner have found themselves with only highly complicated regulatory systems and impaired insurance markets. Regulatory complexity grows as additional components are added in an attempt to counteract the unintended consequences of existing regulations. However, the experience of those states that have deregulated rates shows that reducing regulatory restrictions is a better solution than adding additional restrictions.

\section{Conclusions}

The objectives of insurance rate regulation can generally be characterized as a desire to achieve universal insurance coverage and to assure reasonable rates for all consumers, while maintaining insurer solvency. The case against rate regulation arises not from disagreement with these objectives, but from the inherent difficulties of achieving them through price regulation in a competitive marketplace. Regulations cannot eradicate the underlying incentive forces that govern decisions in markets, and regulations that ignore these forces lead to unintended consequences that worsen market outcomes.

The academic literature on insurance market regulation suggests a near consensus among insurance scholars that the main effect of insurance rate regulation is to impose efficiency losses in an otherwise reasonably competitive marketplace. Rate regulation distorts market functioning in many ways. Regulatory attempts to reduce prices by holding down insurer profits have been shown to adversely affect insurance availability and to distort market structure. Regulatory pricing that is substantially below risk-based premiums for some consumers has been shown to lead to larger residual markets and to higher average insurance costs for all. 
Concerns about insurance availability and affordability for many consumers may in fact be lessened by deregulating insurance rates, thereby allowing insurer competition and providing consumers' incentives for risk reduction. States that have loosened insurance rate regulation have indeed seen increased competition and lower prices. Thus, both theory and experience suggest that the marketplace may promote regulatory objectives more effectively than state intervention.

Regulatory reforms that reduce state intervention in pricing would clearly improve the functioning of the insurance system. States that feel the need for some regulatory oversight would be advised to move to flex-rating with wide approval bands or file-and-use regulation rather than prior-approval. If insurance affordability for high-risk consumers is a concern, subsidized residual market pools appear to function effectively in providing insurance for the small fraction of consumers who cannot otherwise obtain insurance in competitive markets. Many states have moved in this direction, but change is uneven across both states and time as some states have a history of responding to insurance market problems by strengthening rate regulation.

The current proposals for optional federal chartering of insurance companies, which would eliminate state (and federal) regulation of insurance rates and risk classification, are another possible avenue for achieving rating reforms. Support for these proposals from some segments of the insurance industry has arisen in part due to the distorting effects of state regulation and frustration over attempts to achieve meaningful and lasting reforms at the state level. ${ }^{15}$

\footnotetext{
${ }^{15}$ See Harrington (2006) for an in depth discussion of the issues surrounding optional federal chartering of insurance companies.
} 
Although a federal charter is no guarantee that regulation of the pricing process will not arise, federal regulators should be less likely than state regulators to enact new regulations in response to changes in local market conditions. Thus, federal regulation could be expected to be more uniform across markets and less changeable over time. In discussions of state versus federal regulation, the flexibility to allow for differing regulatory responses to differing local market conditions is usually thought to be an advantage of state regulation. The experience of insurance rate regulation suggests that this flexibility may not always lead to the adoption of efficient regulations by all jurisdictions. 


\section{Bibliography}

Abraham, K.S., 1985, Efficiency and Fairness in Insurance Risk Classification, Virginia Law Review 71: 403-451.

Barkume, A. and J. Ruser, 2001, Deregulating Property-Casualty Insurance Pricing: The Case of Workers' Compensation, Journal of Law and Economics 44: 37-64.

Bartlett, D.K. III, R.W. Klein and D.T. Russell, 1999, Attempts to Socialize Costs in Voluntary Insurance Markets: The Historical Record, Journal of Insurance Regulation 17: 478-511.

Blackmon, B.G. Jr. and R. Zeckhauser, 1991, Mispriced Equity: Regulated Rates for Auto Insurance in Massachusetts, American Economic Review 81: 65-69.

Bond, E., and K.C. Crocker, 1991, Smoking, Skydiving and Knitting: Endogenous Categorization of Risks in Insurance Markets with Asymmetric Information, Journal of Political Economy 99: 177-200.

Boyer, M. and G. Dionne, 1989, An Empirical Analysis of Moral Hazard and Experience Rating, Review of Economics and Statistics 71: 128-134.

Buchmueller, T. and J. DiNardo, 2002, Did Community Rating Introduce an Adverse Selection Death Spiral? Evidence from New York, Pennsylvania and Connecticut, American Economic Review 92: 280-294.

Clark, J.M., 1940, Toward a Concept of Workable Competition, American Economic Review 30.

Cummins, J.D., R.D. Phillips and M.A. Weiss, 2004, Incentive Effects of No-Fault Automobile Insurance, The Journal of Law and Economics 47: 427-464. 
Cummins, J.D., R.D. Phillips, and S. Tennyson, 2001, Regulation, Political Influence, and the Price of Automobile Insurance, Journal of Insurance Regulation 20: 9-50.

Cummins, J.D. and S. Tennyson, 1996, Moral Hazard in Insurance Claiming: Evidence from Automobile Insurance, Journal of Risk and Uncertainty 12: 29-50.

Cummins, J.D. and S. Tennyson, 1992, Controlling Automobile Insurance Costs, Journal of Economic Perspectives 6: 95-115.

Dahlby, B., 1983, Adverse Selection and Statistical Discrimination: An Analysis of Canadian Automobile Insurance, Journal of Public Economics 20: 121-130.

Dahlby, B. 1992, Testing for Asymmetric Information in Canadian Automobile Insurance, in: Georges Dionne, ed., Contributions to Insurance Economics. Boston: Kluwer Academic Publishers.

Danzon, P.M. and S.E. Harrington, 2001, Workers' Compensation Rate Regulation: How Price Controls Increase Costs, Journal of Law and Economics 44: 1-36.

Derrig, R.A., 1993, Price Regulation in US Automobile Insurance: A Case Study of Massachusetts Private Passenger Automobile Insurance 1978-1990, The Geneva Papers on Risk and Insurance 18: 158-173.

Grabowski, H., W.K. Viscusi, and W.N. Evans, 1989, Price-Availability Tradeoffs of Automobile Insurance Regulation, Journal of Risk and Insurance 56: 275-299.

Grace M.F., R.W. Klein, and R.D. Phillips, 2002, Auto Insurance Reform: Salvation in South Carolina, in J. D. Cummins, ed. Deregulating Property-Liability Insurance. (Washington, D.C.: Brookings Institution Press), 148-194. 
Harrington, S.E., 1984, The Impact of Rate Regulation on Prices and Underwriting Results in the Property-Liability Insurance Industry: A Survey, Journal of Risk and Insurance 51: 577-623.

Harrington, S.E., 1987, The Impact of Rate Regulation on Auto Insurance Loss Ratios: Some New Evidence, Journal of Insurance Regulation, 5, 182-202.

Harrington, S.E., 1990, The Relationship between Voluntary and Involuntary Market Rates and Rate Regulation in Automobile Insurance, Journal of Risk and Insurance 57: 9-27.

Harrington, S.E., 1992, Rate Suppression, Journal of Risk and Insurance 59: 185-202. Harrington, S.E., 2002, Effects of Prior Approval Rate Regulation of Auto Insurance, in J. D. Cummins, ed. Deregulating Property-Liability Insurance. (Washington D.C.: Brookings Institution Press), 285-314.

Harrington, S.E., 2006, Federal Chartering of Insurance Companies: Options and Alternatives for Transforming Insurance Regulation. Networks Financial Institute Policy Brief (2006-PB-2).

Harrington, S.E. and H.I. Doerpinghaus, 1993, The Economics and Politics of Automobile Insurance Rate Classification, Journal of Risk and Insurance 60: $59-84$.

Harrington, S.E. and P.M. Danzon, 2000, Rate Regulation, Safety Incentives and Loss Growth in Workers Compensation Insurance, Journal of Business 73: 569-96. Jaffee, D.M. and T. Russell, 1998, The Causes and Consequences of Rate Regulation in the Auto Insurance Industry, in David F. Bradford, ed., The Economics of Property-Casualty Insurance (Chicago: University of Chicago Press). 
Joskow, P., 1973, Cartels, Competition and Regulation in the Property Liability Insurance Industry, Bell Journal of Economics and Management Science 4: 375-427.

Keeton, W.R. and E. Kwerel, 1984, Externalities in Automobile Insurance and the Underinsured Driver Problem, Journal of Law and Economics 27: 149-179.

Monheit, A.C., Steinberg Schone, B., 2003, How Has Small Group Market Reform Affected Employee Health Insurance Coverage? Journal of Public Economics 88: 237-254.

Pauly, M.V., 1970, The Welfare Economics of Community Rating, Journal of Risk and Insurance 37: 407-418.

Pauly, M., H. Kunreuther, and P. Kleindorfer, 1986, Regulation and Quality Competition In the U.S. Insurance Industry, In J. Finsinger and M. Pauly, eds., The Economics of Insurance Regulation (London: Macmillan).

Rea, S.A., 1992, Insurance Classifications and Social Welfare, in Contributions to Insurance Economics, G. Dionne, ed., Boston: Kluwer Academic Publishers.

Riley, J.G., 1979, Informational Equilibrium, Econometrica 47: 331-359.

Rothschild, M. and J.E. Stiglitz, 1976, Equilibrium in Competitive Insurance Markets: An Essay on the Economics of Imperfect Information, Quarterly Journal of Economics 90: 629-649.

Rottenberg, S., 1989, The Cost of Regulated Pricing: a Critical Analysis of Auto Insurance Premium Rate-Setting in Massachusetts, Boston: Pioneer Institute for Public Policy Research.

Scherer, F.M., 1980, Industrial Market Structure and Economic Performance, $2^{\text {nd }}$ edition, Houghton Mifflin. 
Shavell, S. 1986, The Judgment Proof Problem, International Review of Law and Economics 6: 45-58.

Simon, K. 2005, Adverse Selection in Health Insurance Markets? Evidence from State Small-Group Health Insurance Reforms, Journal of Public Economics, 89: 18651877.

Smith, E. and R. Wright, 1992, Why Is Automobile Insurance in Philadelphia So Damn Expensive? American Economic Review 82: 756-72.

Suponcic, S.J. and S. Tennyson, 1998, Rate Regulation and the Industrial Organization of Automobile Insurance, in David Bradford, ed., The Economics of PropertyCasualty Insurance (Chicago: University of Chicago Press).

Swartz, K. and D.W. Garnick, 1999, Can Adverse Selection be Avoided in a Market for Individual Health Insurance? Medical Care Research and Review 56: 373-388.

Tennyson, S., 1997, The Impact of Rate Regulation on State Automobile Insurance Markets, Journal of Insurance Regulation 15: 502-523.

Tennyson, S., M.A. Weiss and L. Regan, 2002, Automobile Insurance Regulation: The Massachusetts Experience, in J. David Cummins, ed., Deregulating PropertyLiability Insurance: Restoring Competition and Increasing Market Efficiency, Washington, D.C.: AEI-Brookings Joint Center for Regulatory Studies.

Weisberg, H.I. and R.A. Derrig, 1991, Fraud and Automobile Insurance: A Report on Bodily Injury Claims in Massachusetts. Journal of Insurance Regulation, 10, 497541. 
Weiss, M.A., L. Regan and S. Tennyson, 2005, Incentive Effects of Automobile Insurance Rate Regulation on Loss Costs and Accident Frequency, paper presented at the $1^{\text {st }}$ annual meetings of WRIEC, Salt Lake City, August 2005.

Yelen, S., 1993, Withdrawal Restrictions in the Automobile Insurance Market, The Yale Law Journal 102: 1431-55. 